\title{
Repercussão da visão monocular após trauma ocular
}

\author{
Impact of monocular vision after ocular trauma \\ Impacto de la visión monocular post trauma ocular
}

\author{
Joselany Afio Caetano', Maria Alzete Lima", Denise Araújo Silva"I", Jennara Cândido do Nascimento" \\ ' Universidade Federal do Ceará, Departamento de Enfermagem, \\ Programa de Pós Graduação em Enfermagem. Fortaleza-CE, Brasil. \\ " Universidade Federal do Ceará, Programa de Pós Graduação em Enfermagem. (Mestranda) \\ Fortaleza-CE, Brasil. \\ II' Hospital Batista. Fortaleza-CE, Brasil.
}

Submissão: 21-07-2010 Aprovação: 13-12-2011

\section{RESUMO}

Pesquisa qualitativa convergente assistencial, que objetivou identificar percepções e significados referentes à perda visual de pacientes que apresentavam visão monocular devido ao trauma ocular. Participaram seis vítimas de trauma ocular com visão monocular, de um hospital referência em emergência. Os dados emergiram das falas das pessoas no grupo de convivência e de entrevistas semiestruturadas. Os resultados demonstraram expectativa de voltar a enxergar, dúvida quanto ao diagnóstico e ausência de acompanhamento, o qual despertou sentimento de angústia e situação conflituosa relacionada à perda da independência. O grupo de convivência foi considerado um elemento que contribuiu para um viver mais saudável, ao promover a troca de experiências e o compartilhar de saberes.

Descritores: Enfermagem; Traumatismo; Oftalmologia.

ABSTRACT

Convergent-care qualitative research, that aimed to identify perceptions and meanings related to visual loss in patients with monocular vision due to ocular trauma. Participants were six victims of ocular trauma with monocular vision, from a reference hospital in emergency. Data emerged from the speeches of people in the living group and from semi-structured interviews. The results showed the expectative to see again, the doubt on the diagnosis and lack of monitoring, which arouse the feeling of anguish and conflict situation related to loss of independence. The living group was considered a contributor to a healthier life by promoting the exchange of experiences and knowledge.

Key words: Nursing; Trauma; Ophthalmology.

\section{RESUMEN}

Investigación cualitativa convergente asistencial, que tuvo como objetivo identificar percepciones y significados relacionados con la pérdida visual en pacientes con visión monocular debido al traumatismo ocular. Los participantes fueron seis víctimas de trauma ocular con visión monocular, de un hospital de referencia en emergencia. Los datos surgieron de la voz de las personas en el grupo de convivencia y de entrevistas semiestructuradas. Los resultados mostraron espera de volver a ver, duda sobre el diagnóstico y falta de acompañamiento, lo que provocó angustia y situación de conflicto relacionado con la pérdida de la independencia. El grupo de convivencia ha sido considerado colaborador para uno vivir saludable al promover el intercambio de experiencias y conocimientos.

Palabras clave: Enfermería, Trauma; Oftalmología. 


\section{INTRODUÇÃO}

O traumatismo ocular, atualmente considerado causa evitável de cegueira, é considerado um significativo problema de saúde incapacitante que afeta todas as faixas etárias ${ }^{(1)}$. Evidências clínicas apontam existir relação entre limitação visual e a manutenção da qualidade de vida. Justifica-se que a transição para a visão monocular pode ser um processo difícil para o paciente, com repercussões que perpassam o envolvimento ocular ${ }^{(2)}$.

O impacto nas atividades ou no estilo de vida repercute sobre o processo de recuperação e/ou reabilitação, sendo um desafio não apenas para o paciente, mas também para os familiares, educadores e profissionais de saúde envolvidos nesse processo.

Considerando-se que a perda da visão, ainda que parcial, coloca o indivíduo em uma condição de deficiente ${ }^{(3)}$, especificamente considerando vítimas de traumatismos, isso se revela de forma abrupta, o que justifica estudos sobre a forma como esse indivíduo se percebe no mundo, sendo possuidor de visão monocular. Assim, este estudo teve por objetivo identificar percepções e significados referentes à perda visual de pacientes que apresentavam visão monocular devido a um trauma ocular.

Entender o significado atribuído pelos indivíduos aos distúrbios da própria saúde é importante, pois ajuda aos enfermeiros a viabilizar práticas educativas com base na forma de pensar, sentir e agir do portador de visão monocular após trauma ocular, e, assim, na busca por sua adesão ao tratamento indicado. Estratégias podem ser instituídas para prevenir e tratar afecções passíveis de correção.

\section{METODOLOGIA}

Pesquisa convergente-assistencial, que incluiu ação do pesquisador na situação social, a fim de solucionar ou amenizar problemas e realizar mudanças. Nesta, destaca-se o pensamento crítico atrelado à prática, na busca pela melhoria assistencial ${ }^{(4)}$.

Desenvolvido em unidade de emergência oftalmológica em serviço público, com capacidade instalada para atender em média trinta pacientes por dia. No serviço, eram realizados grupo de convivência de pacientes internados que apresentaram visão monocular após trauma ocular, com o objetivo de executar ações de educação em saúde. O grupo apresentava como finalidade compartilhar saberes e experiências na construção de um viver mais saudável, buscando por formar uma rede de suporte social, promover a autonomia de seus integrantes, ampliar a criatividade, melhorar a autoimagem, oportunizar a livre expressão dos participantes sobre suas emoções e seus conhecimentos, e estabelecer articulações com outros grupos e instituições ${ }^{(5)}$.

Para a coleta dos dados, realizaram-se oficinas, que transcorreram em abril de 2007. Depois de desenvolvidas dinâmicas de descontração e relaxamento, abordaram-se assunto de interesse à investigação, como a convivência com a visão monocular após trauma.

O enfoque, nessa proposta, é de uma prática educativa, pois promove a saúde e facilita o processo de ensino-aprendizagem de habilidades e enfrentamentos, para as pessoas em condição crônica de saúde.

O processo educativo sucedeu-se através de seis encontros, denominados de $O$ reconhecimento da visão monocular; Pensando sobre sua nova situação; Refletindo sobre o problema; e O engajamento ao grupo. Nesses encontros, diferentes dinâmicas foram utilizadas, como a técnica de explosão de ideias, da batata quente, da introspecção, dos provérbios, momentos de descontração e festa junina. Em todos os encontros, havia um tema central, escolhido pelos integrantes, que vivenciavam, de diferentes maneiras, o processo de aceitação do viver com limitação visual, sendo que, em todos esses encontros, discutiu-se de forma direta e indireta as múltiplas facetas que compunham esse cotidiano.

A coleta de dados foi realizada em duas etapas: a primeira durante a execução do grupo de convivência e a segunda através de entrevistas individuais, semiestruturadas. As entrevistas foram realizadas mediante perguntas norteadoras: conte-me sobre a sua vida, antes e depois do trauma ocular; e o significado do acidente no seu cotidiano. Foram gravadas e transcritas, submetidas à análise, seguindo recomendação da literatura, através de leituras e releituras dos encontros e das entrevistas; codificação dos dados; seleção dos códigos referentes ao processo de viver com visão monocular após trauma ocular; elaboração de categorias; e interpretação dos achados.

Obteve-se o Consentimento Livre e Esclarecido de todos os participantes, garantindo-lhes sigilo e anonimato, mediante a utilização dos códigos P1, P2, P3, e assim sucessivamente, obedecendo a uma ordem cronológica das entrevistas. Os princípios éticos estiveram em acordo com a Resolução n 196/96, do Conselho Nacional de Saúde ${ }^{(6)}$, tendo sido o projeto aprovado pelo Comitê de Ética da instituição, pelo Parecer n 529/2004.

\section{RESULTADOS}

A análise dos dados permitiu identificar percepções e significados referentes à perda visual de pacientes que apresentavam visão monocular devido ao trauma ocular. Ao compartilhar experiências no grupo, evidenciaram-se anseios, necessidades, revoltas e medo vivenciados pelo grupo, bem como dificuldades.

No processo de análise dos dados, foram identificados temas que representavam barreiras: dificuldade de aceitação da visão monocular; desinformação; incerteza do futuro; perda da autonomia e participação do grupo.

A dificuldade de aceitação da perda da visão geralmente é a primeira reação. Aquele que, antes era normal, agora se torna um deficiente e sente-se ansioso e temeroso diante dos desafios a serem enfrentados em virtude de sua nova condição. Trata-se de um processo complexo, que envolve diversos aspectos na vida do indivíduo.

Importante entender que esta nova situação ocorre de maneira repentina, o que muitas vezes confronta o sujeito do sofrimento com algo inesperado. Isso revela a dificuldade de aceitação da sua nova condição.

O comprometimento visual desencadeia um processo de alteração emocional e psicológica ${ }^{(7)}$. Alguns sentimentos 
Dificuldade de aceitação da visão monocular: Sinto vergonha, antes eu era normal e agora sou deficiente. Tem dia que eu choro de tristeza, sabe?(P1). [...] a gente perde a esperança do futuro, da vida. Não consigo sair de casa, a gente sente um medo muito grade (P3). [...] estou muito triste com o fato de estar cego, não sei como vai ser minha vida a partir de agora, porque acho que vou sofrer uma série de restrições [...] (P4). Tenho um medo muito grande de sair sozinho (P6).[...] é muito triste agente perder a vista [...] (P2).

Desinformação: A gente não é informado no hospital se dá para enxergar ou não, no começo nem sabia se tinha como recuperar minha visão e nem quem procurar pra me ajudar. Eu sofro muito, porque não sei como vai ser o tratamento [...] Não sei como faço, porque o hospital não informa para onde a gente deve procurar pra cuidar do olho que ainda não tá bom (P1). Ninguém no hospital tinha coragem para me dizer que eu fiquei cego [...] eu perguntei várias vezes, mas ninguém me falava nada [...] (P5).

Incerteza sobre o futuro: [...] não sei como vai ser. Nunca mais vou ter oportunidade de emprego, trabalho (P6). [...] me tornei muito dependente das pessoas (P1). Toda vida trabalhei. Depois do acidente eu passei a viver só em casa, e me tornei muito dispendioso financeiramente (P4).

Participação no grupo: As reuniões do grupo são importantes. Nós aprendemos a caminhar, a encontrar outros caminhos (P2). Agente sempre se acha um coitadinho, ouvindo os outros passa a ser menos doloroso, sei que outros sentem a mesma coisa, fico me sentido melhor sabe (P5); Ter o grupo, ter onde falar dos problemas, isso ajuda a dar força (P3). Os encontros possibilitaram a troca de conhecimentos, experiência, e juntos crescemos. É um momento de energia positiva (P2).

\section{Quadro 1 - Categorias e falas dos entrevistados}

estão frequentemente associados a essa condição, como o luto, que pode ser interpretado como uma tentativa reiterada do ego em continuar a investir no objeto perdido, provocando desinteresse pelo mundo externo e dificuldade de encontrar outro objeto de atenção. Tudo gira em torno dessa perda ${ }^{(8)}$.

Pôde-se analisar, nas falas dos entrevistados, que sentimentos variados acompanharam a nova situação das vítimas de trauma ocular, como vergonha, tristeza, medo, impotência, perda da esperança e restrições. Enfatiza-se que o medo é um sentimento de impotência, um ver-se ameaçado por algo iminente, cuja força supera os mecanismos de defesa pessoais. Ele pode estar relacionado às incertezas que cercam o processo que se segue após o trauma e às dificuldades encontradas na busca por uma adaptação melhor ${ }^{(9)}$.

A insuficiente aceitação social e individual e as projeções pessimistas também permeiam as declarações. Acrescenta-se que a limitação corporal ou mental podem afetar o comportamento e originar aspectos ora atípicos, fortes e adaptativos, ora fracos e pouco funcionais ${ }^{(10)}$. O sentimento de exclusão, aliado à falta de aceitação pessoal ocasiona, muitas vezes, o desenvolvimento de conflitos internos, o que justifica a necessidade de desenvolvimento de habilidade do profissional enfermeiro em lidar com esse tipo de paciente de forma holística, atendendo às suas necessidades e promovendo a integridade física, mental e emocional.

Além das dificuldades de cunho pessoal, foram apontadas dificuldades na obtenção de informações sobre o problema ocular sofrido. Três dos entrevistados não sabiam que tinham perda permanente da visão. Pesquisa semelhante destacou que muitos não se submetem à consulta médica posterior, em razão da demora em conseguir atendimento e/ou pela falta de acesso às informações necessárias sobre como proceder diante de problema ocular ${ }^{(8)}$.

Observam-se, com frequência, o desconhecimento da real situação e a inexistência de orientação sobre o problema pelos profissionais de saúde. Esta questão foi apontada como causadora de dor e sofrimento, associados ao sentimento de impotência. Destaca-se a ênfase negativa presente nos discursos, achados que se assemelham com outros estudos $^{(7-8)}$. Os participantes esperavam que os profissionais de saúde ocupassem um espaço de orientação e diálogo, de modo a facilitar o entendimento acerca da nova situação - a perda da visão.

A dependência foi apontada como o principal fator de dificuldade no contexto do pós-trauma, além da mudança no estilo de vida. Grande parte dos relatos apontou para as dificuldades relacionadas à modificação do papel laboral do indivíduo acometido. A percepção de que a vida antes era ativa e produtiva, passando para calma e dispendiosa financeiramente, após o ocorrido, despontaram como fonte geradora de muitos conflitos internos, que proporciona situação de ansiedade, pela necessidade constante dessa ajuda, e sentimento de impotência em tentativas fracassadas.

Perspectivas sobre o futuro no pós-trauma direcionaram-se para questionamentos pessoais sobre a superação das dificuldades. O contexto social participa decisivamente, refletindo preconceito para com os deficientes e produzindo dúvidas para os que se inserem repentinamente num mercado tão competitivo, fato constatado em seus discursos (Quadro 1).

A perda da autonomia contribui para a diminuição da autoestima. No grupo, as discussões possibilitaram ajudar no processo de superação de alguns preconceitos, evidenciando que as repercussões das discussões influenciavam para além do vivido naquele momento. Acredita-se que o profissional enfermeiro seja capaz de caminhar junto ao portador de deficiência visual na busca por uma integração maior desse grupo e pelo exercício pleno de sua autonomia.

Desse modo, as atividades desenvolvidas no grupo de ajuda proporcionaram suporte e auxiliaram os indivíduos 
no esclarecimento de dúvidas sobre o problema ocular e a aceitação de alguns limites impostos pelo trauma, além de procurar fornecer estímulo para enfrentar o novo. O grupo de convivência favoreceu o pensar coletivo, reforçando reflexões que conduzissem a uma conscientização dos sujeitos.

Nessa perspectiva, trata-se de encontrar alternativas que favoreçam o viver melhor em face da condição de saúde. É ressaltada a importância de pessoas com limitação visual perceberem-se no controle de sua condição e, para isso, é preciso que estejam constantemente aprendendo como lidar com seu problema de saúde, que saibam como monitorar sua condição e como proceder a escolhas que favoreçam a qualidade de vida.

\section{CONSIDERAÇÕES FINAIS}

O estudo possibilitou identificar significados, percepções, sentimentos, reações e experiências relacionados à perda da visão unilateral por trauma. A expectativa de voltar a enxergar, a dúvida quanto ao diagnóstico de cegueira e a ausência de acompanhamento despertaram sentimentos de angústia e situação conflituosa, relacionados à perda da independência. O anseio ao retorno da rotina e de sentir-se útil, e dúvidas relacionadas ao retorno à atividade laboral também permearam a realidade daqueles que se perceberam sem a visão.

Desse modo, reforça-se que o desenvolvimento de ações de educação em saúde em grupos, como alternativa, tem trazido às pessoas resultados efetivos na promoção da saúde, do bem-estar e do viver mais plenamente suas potencialidades. A perspectiva do aprender em saúde que respeita o saber do outro, que é dialógica e comprometida com as mudanças na sociedade, sem dúvida traz importante contribuição para um viver mais saudável de pessoas com limitação visual.

As limitações que a perda da visão pode acarretar devem ser entendidas como passíveis de serem superadas, ou, pelo menos, amenizadas. Para isso, o indivíduo deve aprender a reorganizar a vida, a rever as possibilidades e buscar por alternativas para lidar com as limitações, superando as dificuldades que envolvem o viver com limitação visual, e promover a mudança de comportamento e busca pelo apoio social.

O desenvolvimento de tecnologia educacional em saúde surge como uma estratégia de promoção de conhecimentos e habilidades, oferecendo suporte aos portadores de limitação visual. Tem como objetivo ajudar o indivíduo a desenvolver efetivamente o seu autocuidado, bem como esclarecer sobre o problema ocular e os limites impostos pelo trauma. A discussão em grupo proporciona o pensar coletivo, reforçando as reflexões que conduzem a uma conscientização dos sujeitos.

Ademais, acredita-se que o profissional enfermeiro seja capaz de caminhar junto ao portador de deficiência visual na busca por uma integração maior desse grupo e pelo exercício pleno de sua autonomia. O caminhar é no intuito de encontrar alternativas para viver melhor em face da condição de saúde.

\section{REFERÊNCIAS}

1. Shah A, Blackhall K, Ker K, Patel D. Educational interventions for the prevention of eye injuries. Cochrane Database Syst Rev. 2009;7(4):CD006527.

2. Morales LS, Varma R, Paz SH, Lai MY, Mazhar K, Andersen RM et al. Self-reported use of eye care among Latinos: the Los Angeles Latino Eye Study. Ophthalmology 2010;117(2):207-15.

3. Lima MA, Pagliuca LMF, Almeida PC, Andrade LM, Caetano JA. Levantamento dos casos de traumatismo ocular num hospital de emergência. Rev. RENE 2010;11(1):58-65.

4. Trentini M, Paim L. Pesquisa convergente assistencial: um desenho que une o fazer e o pensar na prática assistencial em Saúde-Enfermagem. 2a . ed. Florianópolis (SC): Insular; 2004.

5. Francioni FF, Silva DGV. O processo de viver saudável de pessoas com diabetes mellitus através de um grupo de convivência. Texto Contexto Enferm. 2007;16(1):105-11

6. Ministério da Saúde (BR). Conselho Nacional de Saúde.
Comissão de Ética em Pesquisa. Resolução n. 196, de 10 de outubro de 1996. Brasília (DF): Ministério da Saúde; 1996.

7. Walber VB, Silva RN. As práticas de cuidado e a questão da deficiência: integração ou inclusão. Estud. Psicol. (Natal) 2006;23(1):29-37.

8. Marback RF, Temporini ER, Maia OO, Kara-Júnior N. Significações atribuídas por portadores de visão monocular à perda visual e cirurgia de catarata. Medicina (Ribeirão Preto) 2007; 40(4):576-81.

9. Roberts NP, Kitchiner NJ, Kenardy J, Bisson JI. Early psychological interventions to treat acute traumatic stress symptoms. Cochrane Database Syst Rev. 2010;3.

10. McCutcheon VV, Heath AC, Nelson EC, Bucholz KK, Madden PA, Martin NG. Clustering of trauma and associations with single and co-occurring depression and panic attack over twenty years. Twin Res Hum Genet. 2010;13(1):57-65. 